\title{
ASSÉDIO MORAL NO ÂMBITO DA ENFERMAGEM: REVISÃO INTEGRATIVA DA LITERATURA
}

Suênia Isabel Leite dos Santos ${ }^{1}$, Cristiani Garrido de Andrade², Isabelle Cristinne Pinto Costa ${ }^{3}$, Kamyla Félix de Oliveira dos Santos ${ }^{4}$, Solange Fátima Geraldo da Costa ${ }^{5}$, Jael Rúbia Figueiredo de Sá França ${ }^{6}$

\begin{abstract}
RESUMO: Objetivou-se sintetizar a produção científica acerca da prática do assédio moral no âmbito da Enfermagem, em periódicos disponíveis online, no período de 2005 a novembro de 2012. Trata-se de uma revisão integrativa da literatura realizada através das bases de dados da Literatura Latino-Americana e do Caribe em Ciências da Saúde, do Índice Bibliográfico Espanhol em Ciências da Saúde e da Literatura Internacional em Ciências da Saúde. A análise de 15 artigos revelou que a prevalência da prática do assédio moral na Enfermagem tem crescido, de forma significativa, essencialmente entre os trabalhadores do sexo feminino. As investigações mostraram que o assédio moral acarreta sérias consequências para a saúde do trabalhador, sendo estas, em sua maioria, de ordem psicológica. Logo, verifica-se a necessidade da criação de propostas para prevenção e até mesmo eliminação de tal prática.
\end{abstract}

DESCRITORES: Estresse psicológico; Saúde do trabalhador; Enfermagem.

\section{ASEDIO MORAL EN EL ÁMBITO DE LA ENFERMERÍA: REVISIÓN INTEGRATIVA DE LA LITERATURA}

RESUMEN: Fue objetivo de este estudio sintetizar la producción científica acerca de la práctica del asedio moral en el ámbito de la Enfermería, en periódicos disponibles online, en el periodo de 2005 a noviembre de 2012. Esta es una revisión integrativa de la literatura realizada por medio de las bases de datos de la Literatura Latinoamericana y del Caribe en Ciencias de la Salud, del Índice Bibliográfico Español en Ciencias de la Salud y de la Literatura Internacional en Ciencias de la Salud. El análisis de 15 artículos reveló que la prevalencia de la práctica del asedio moral en la Enfermería ha crecido de forma significativa esencialmente entre los trabajadores del sexo femenino. Las investigaciones muestran que el asedio moral trae graves consecuencias para la salud del trabajador, siendo estas, en su mayoría, de orden psicológico. Luego, se verifica la necesidad de la creación de propuestas para prevención y, incluso, eliminación de tal práctica. DESCRIPTORES: Estrés psicológico; Salud del trabajador; Enfermería.

\section{PSYCHOLOGICAL HARASSMENT IN THE AMBIT OF NURSING: AN INTEGRATIVE LITERATURE REVIEW}

\begin{abstract}
The aim was to synthesize the scientific production regarding the practice of psychological harassment in the ambit of Nursing, in periodicals available online, in the period January 2005 - November 2012. This is an integrative review of the literature, undertaken using the following databases: the Latin American and Caribbean Center on Health Sciences Information, the Spanish Bibliographic Index on Health Sciences, and the International Literature in Health Sciences. The analysis of 15 articles revealed that the prevalence of the practice of psychological harassment in Nursing has grown significantly, particularly among female workers. The investigations showed that psychological harassment entails serious consequences for the worker's health, most of which are of a psychological nature. Thus, the need is verified for creating proposals for the prevention and even elimination of this practice.
\end{abstract}

DESCRIPTORS: Stress psychological; Occupational health; Nursing.

\footnotetext{
${ }^{1}$ Enfermeira. Universidade Federal da Paraíba. João Pessoa-PB-Brasil

${ }^{2}$ Enfermeira e Fonoaudióloga. Especialista em Saúde Coletiva. Mestranda em Enfermagem. Universidade Federal da Paraíba. Professora da Faculdade de Ciências Médicas da Paraíba. João Pessoa-PB-Brasil

${ }^{3}$ Enfermeira e Fonoaudióloga. Mestre em Enfermagem. Doutoranda em Enfermagem. Universidade Federal da Paraíba. João PessoaPB-Brasil

${ }^{4}$ Enfermeira. Mestranda em Enfermagem. Universidade Federal da Paraíba. João Pessoa-PB-Brasil

${ }^{5}$ Enfermeira. Doutora em Enfermagem. Professora da Universidade Federal da Paraíba. João Pessoa-PB-Brasil

${ }^{6}$ Enfermeira. Mestre em Enfermagem. Doutoranda em Enfermagem. Universidade Federal da Paraíba. João Pessoa-PB-Brasil
} 


\section{INTRODUÇÃO}

As transformações que acontecem no mundo do trabalho, ocasionadas por fatores econômicos e políti$\cos$, têm levado à exploração da mão de obra humana, o que expõe os profissionais a situações desgastantes, e fere a condição humana do sujeito trabalhador. Desde o advento do capitalismo, os donos do capital não medem esforços para obter o lucro e a produtividade, finalidades primordiais desse sistema. Destarte, essa conduta de parcela do gênero humano, e o descaso quanto à dimensão da subjetividade decorrente desse, favorecem o surgimento do sofrimento e da violência no trabalho ${ }^{(1)}$.

É oportuno destacar que essa violência é caracterizada como assédio moral, que por sua vez se refere a práticas de humilhações, perseguições e ameaças nos locais de trabalho, às quais os trabalhadores estão expostos. O fenômeno se dá por meio de uma violência psicológica, sutil, dissimulada, intencional, que acontece de maneira repetitiva e por um período prolongado de tempo, com a intenção de humilhar e excluir socialmente o trabalhador das suas atividades profissionais ${ }^{(2)}$.

Desse modo, constata-se que o assédio moral ocorre de forma insidiosa, com implicações desastrosas para a vítima e para a sociedade, violentando a dignidade humana do assediado. Dessa forma, o fato se mostra como um problema ético, uma vez que perpassa os direitos fundamentais do ser humano. Esses pontos devem ser rigorosamente considerados, pois tendem a aumentar em paralelo com o aumento da agressão psicológica sofrida pelo trabalhador ${ }^{(3)}$.

Ressalta-se que a prática do assédio moral afeta a integridade física e/ou psicológica de um indivíduo, o que pode ocasionar depressões, angústias, insegurança, insônia, falta de iniciativa, estresse, dores, disfunções no aparelho respiratório, podendo chegar a arriscar, de forma fatal, a vida da vítima ${ }^{(4)}$.

O assédio moral pode ocorrer de quatro maneiras distintas, que variam conforme a posição hierárquica da vítima e do assediador no processo de trabalho: 1) o assédio descendente, em que o subordinado é agredido por um superior, sendo considerada a mais grave e frequente; 2) o assédio horizontal, que é aquele em que a agressão é efetivada por um colega de trabalho do mesmo nível hierárquico; 3) o assédio ascendente, que se configura quando um superior é assediado por um ou vários subordinados; 4) o assédio misto, quando ocorre, simultaneamente, mais de uma forma de assédio ${ }^{(5)}$.

Neste estudo, descreve-se que a prática do assédio moral tem sido observada nos mais diversos cenários de trabalho em saúde, seja em serviço público ou privado, sobretudo, no campo da Enfermagem, podendo, inclusive, ser realizado pelos próprios colegas de trabalho, ou ainda por chefes de serviços ou por outros profissionais que compõem a equipe de saúde ${ }^{(6)}$.

Cabe destacar que a discussão acerca do assédio moral vem ganhando popularidade no contexto atual devido à intensificação e ao agravamento do fenômeno, haja vista que esse acontecimento vem ocorrendo acentuadamente em outros tipos de relacionamentos sociais, para além da esfera do trabalho. Entretanto, a referida prática ainda é mal dimensionada nesses cenários. Assim, considerando a relevância dessa temática no âmbito da Enfermagem, afirma-se a necessidade da realização de mais pesquisas acerca dessa prática, que possam colaborar com o aumento da visibilidade social desse problema, que afeta, cada vez mais, e de forma silenciosa e irreversível, a saúde do trabalhador.

Em face das considerações apresentadas, este estudo teve como objetivo sintetizar a produção científica acerca da prática do assédio moral no âmbito da Enfermagem, em periódicos online, no período de 2005 a novembro de 2012 .

\section{MÉTODO}

Para o alcance do objetivo proposto, selecionou-se como método de pesquisa a revisão integrativa da literatura, que possibilita uma investigação científica de maneira sistemática e ampliada, de modo a apresentar o conhecimento produzido por estudos antecedentes ${ }^{(7)}$. Para tanto, foram delimitadas as seguintes etapas metodológicas: realização da amostragem (seleção dos artigos); categorização dos estudos; definição das informações extraídas das publicações revisadas; avaliação dos estudos selecionados; interpretação e apresentação dos resultados da pesquisa ${ }^{(7-8)}$.

Para o levantamento do material bibliográfico sobre a temática sugerida para a condução deste estudo, foram realizadas buscas nas bases de dados da Literatura Latino-Americana e do Caribe em Ciências da Saúde (LILACS), do Índice Bibliográfico Espanhol em Ciências da Saúde (IBECS) e da Literatura Internacional em Ciências da Saúde (MEDLINE). A escolha por essas bases de dados deve-se ao fato de elas englobarem publicações nacionais e internacionais. Para a busca, utilizaram-se os seguintes descritores em Ciências da Saúde (DeCS) e do Medical Subjetc Headings - MeSH, em português, inglês e espanhol: "Estresse", "Saúde Ocupacional" e "Violência", os 
quais foram combinados por meio do operador booleano "AND," com o descritor "Enfermagem".

Cumpre assinalar que foram adotados os seguintes critérios de inclusão: artigos publicados no período de 2005 a novembro de 2012, nos idiomas português, inglês e/ou espanhol, cujos títulos e/ou resumos contemplassem aspectos relativos ao assédio moral no âmbito da Enfermagem e estivessem disponibilizados na íntegra, gratuitamente, e online. Foram excluídos os editoriais, cartas ao editor, estudos reflexivos, relatos de experiência, publicações duplicadas, assim como estudos que não abordassem temática relevante ao objetivo da revisão. A coleta de dados ocorreu durante o mês de novembro de 2012.

Após análise das publicações, em que se buscou atender aos critérios de pertinência e consistência do conteúdo, encontraram-se 22 que responderam aos critérios previamente estabelecidos, e destes, sete foram excluídos por estarem citados em mais de uma base de dados. Portanto, a amostra efetiva foi composta por 15 artigos.

$\mathrm{Na}$ fase seguinte, os dados obtidos por meio do material reunido (oriundo dos trechos extraídos das publicações) foram organizados em planilhas, com agrupamento das informações de acordo com a relevância e a equivalência às categorias temáticas que configuram a finalidade principal deste estudo. Depois

Tabela 1 - Distribuição dos artigos sobre assédio moral na Enfermagem, segundo os periódicos científicos. Janeiro 2005 a novembro 2012. João Pessoa-PB-Brasil, 2012

\begin{tabular}{lcc}
\hline PERÍODICO & n & \% \\
\hline Revista Brasileira de Saúde & 2 & 13,33 \\
Ocupacional & 2 & 13,33 \\
Revista Gaúcha de Enfermagem & 1 & 6,66 \\
Caderno de Saúde Pública & 1 & 6,66 \\
Cogitare Enfermagem & 1 & 6,66 \\
Revista da Escola de & 1 & 6,66 \\
Enfermagem da USP & 1 & 6,66 \\
Acta Paulista de Enfermagem & 1 & 6,66 \\
Nursing Research and Practice & 1 & 6,66 \\
Rournal of Nursing Scholarship & 1 & 6,66 \\
Enfermagem & 1 & 6,66 \\
Journal of Clinical Nursing & 1 & 6,66 \\
International Journal of Environ- \\
mental ResearchandPublicHealth & 1 & 6,66 \\
Index de Enfermería & 1 & 100 \\
\hline $\begin{array}{l}\text { Revista de la Sociedad Española } \\
\text { de Enfermería Nefrológica }\end{array}$ & 15 & \\
\hline Total & & \\
\hline
\end{tabular}

dessa planificação e da organização, foi realizada a análise temática dos referidos dados.

\section{RESULTADOS}

Das quinze publicações encontradas, oito $(53,33 \%)$ foram editadas no idioma português, cinco $(33,33 \%)$ em inglês e duas $(13,33 \%)$ em espanhol. No que concerne à base de dados, oito estudos $(53,33 \%)$ foram encontrados na LILACS, cinco publicações $(33,33 \%)$ foram selecionadas através da MEDLINE, e na IBECS foram encontrados apenas dois artigos (13,33\%).

Quanto ao ano de publicação, observou-se que 2011 e 2012 corresponderam aos períodos com maior número de artigos científicos publicados, com quatro produções $(26,66 \%)$ cada, seguidos dos anos de 2005 e 2008, com dois estudos (13,33\%) cada. Os anos de 2006, 2007 e 2009 apresentaram apenas um artigo (6,66\%), cada. Constatou-se que, em 2010, não houve publicações acerca do tema proposto.

Em relação aos periódicos, destacaram-se importantes revistas nacionais, dentre as quais merecem evidência a Revista Gaúcha de Enfermagem e a Revista Brasileira de Saúde Ocupacional, com duas produções $(13,33 \%)$ cada, conforme indicado na Tabela 1.

Com relação ao delineamento metodológico dos artigos, ressalta-se que, dos 15 artigos selecionados, $12(80 \%)$ são artigos originais, conforme se mostra na Tabela 2.

Quanto ao conteúdo, o conhecimento documentado pela literatura investigada foi sintetizado em duas categorias temáticas: Assédio moral no âmbito da Enfermagem: prevalência e fatores de risco; e Assédio moral: consequências para a saúde do trabalhador da Enfermagem.

Tabela 2 - Distribuição dos artigos científicos sobre assédio moral na Enfermagem, segundo tipo de estudo. Janeiro 2005 a novembro 2012. João Pessoa-PB-Brasil, 2012

\begin{tabular}{lcc}
\hline TIPO DE ESTUDO & $\mathbf{n}$ & $\mathbf{\%}$ \\
\hline Quantitativo & 2 & 13,33 \\
Qualitativo & 1 & 6,66 \\
Documental & 1 & 6,66 \\
Estudo de caso & 1 & 6,66 \\
Multicêntrico & 1 & 6,66 \\
Retrospectivo & 1 & 6,66 \\
Exploratório transversal & 1 & 6,66 \\
Descritivo transversal & 3 & 20,00 \\
Descritivo & 1 & 6,66 \\
Revisão & 3 & 20,00 \\
\hline Total & 15 & 100 \\
\hline
\end{tabular}




\section{DISCUSSÃO}

Assédio moral no âmbito da Enfermagem: prevalência e fatores de risco

No que concerne aos enfoques da categoria I, os artigos deram ênfase à prevalência do assédio moral em profissionais da equipe de enfermagem, enfatizando, ainda, quais os principais fatores de risco para o surgimento desse tipo de violência no trabalho.

$\mathrm{O}$ assédio moral no ambiente de trabalho se constitui por comportamentos agressivos, cruéis, ameaçadores e humilhantes, exercidos por um indivíduo e/ ou um grupo contra uma mesma pessoa, no intuito de desestabilizá-la psicologicamente. É oportuno destacar que os trabalhadores da Enfermagem têm uma série de características que os tornam particularmente vulneráveis ao assédio, tendo como consequência o aumento da prevalência, quando comparados a outros profissionais da saúde. Entre outras, tais características são: a continuidade do atendimento; a necessidade de resolver problemas que surgem inesperadamente (piora ou morte de pacientes, acidentes); e a alta carga emocional, pois a equipe de enfermagem trabalha constantemente contra a dor e a morte, criando um clima propício ao estresse emocional ${ }^{(9)}$.

Nessa perspectiva, um estudo acerca da violência no trabalho destacou que os profissionais de Enfermagem têm probabilidade três vezes maior que outros profissionais a serem vítimas do assédio moral, uma vez que esses profissionais possuem uma alta carga de trabalho (em jornada horária e conteúdo) e, muitas vezes, urgência em realizar o cuidado. Logo, verifica-se que a violência psicológica advinda da exigência de uma dada forma de cumprimento do trabalho atinge altos níveis epidêmicos, onde $70 \%$ das vítimas são mulheres ${ }^{(10)}$.

Nesse sentido, constata-se, que $30,4 \%$ das vítimas de violência no trabalho relataram sofrer assédio moral, sendo a sua maioria do sexo feminino ${ }^{(10)}$. Tal fato é associado a outro: o de que a grande maioria de trabalhadores é de mulheres nas equipes de enfermagem, podendo sofrer violência resultante do autoritarismo e dominação da equipe médica que, muitas vezes, está representada pela figura masculina; também se sabe da vulnerabilidade da mulher na cultura patriarcal dominante, e que muitas vezes são impedidas de chegar a uma posição de maior responsabilidade ${ }^{(10-11)}$, favorecendo a sua permanência em espaços de submissão e opressão.

Em um serviço de urgência localizado na cidade de Londrina, no Paraná, uma pesquisa revelou situação preocupante de violência psicológica no trabalho sofrida pelos profissionais de Enfermagem. Os resultados indicaram que, dentre 33 desses trabalhadores e 14 médicos, $33 \%$ relataram os assédios moral e sexual como a violência no trabalho mais cometida, sendo que a agressão verbal foi lembrada por $95,2 \%$ dos participantes. Compete esclarecer que a agressão verbal configura assédio moral quando se torna constante e fere a dignidade do trabalhador ${ }^{(12)}$.

Ressalta-se, ainda, que as equipes de enfermagem com profissionais de idades menores de 30 anos e maiores de 44 anos, com menor tempo de atuação no emprego, do sexo feminino e com maior nível de ansiedade, são considerados grupos de risco para o assédio moral ${ }^{(13)}$.

Com relação ao menor tempo de atuação no local de trabalho, autores ${ }^{(14)}$ aludem que $58,4 \%$ dos enfermeiros principiantes são alvos do assédio moral, sendo os principais assediadores colegas de enfermagem mais experientes. Corroborando estes dados, os estudos ${ }^{(13-15)}$ referem que quanto maior o tempo de formação, menor o grau de agressão sofrida. Dessa forma, destaca-se que o assédio moral sobre enfermeiros iniciantes é uma problemática altamente prevalente nos serviços de saúde, onde os novos funcionários necessitam ser esclarecidos para reconhecer esse tipo de comportamento e colaborar para a redução de tal prática.

Além dos aspectos já expostos, existem os que estão relacionados às transformações do mundo moderno, e que tornam o processo de trabalho favorável à prática do assédio moral, como os modelos políticos, econômicos e sociais próprios da lógica do capitalismo, orientados pelo neoliberalismo e pela globalização. Entre os traços mais importantes dessa lógica estão o incentivo à proliferação das privatizações dos serviços, a deterioração das relações interpessoais, a fragilidade dos vínculos empregatícios, a forma precária de contratação, a intensificação pela cobrança de alta produtividade e a desvalorização do salário do trabalhador ${ }^{(11,16)}$.

Também são apontados como aspectos propícios ao aparecimento do assédio moral os conflitos interpessoais presentes no preconceito racial; na xenofobia; diante de incapacidades físicas e mentais; por razões políticas ou religiosas; na condição de migrante; na intolerância pela opção sexual; no fato elementar de a vítima ser ou comportar-se de modo diferente dos demais membros do coletivo de trabalho ${ }^{(16)}$.

É preciso ressaltar que um dos determinantes que caracterizam o assédio moral encontra-se no estímulo descontrolado à competitividade pelo emprego, o que 
origina, diversas vezes, comportamentos nada adequados e pouco éticos advindos de superiores hierárquicos ou mesmo de colegas ${ }^{(1,9)}$. Por outro lado, com o quadro atual de grave desemprego, muitos trabalhadores omitem a ocorrência do assédio moral sobre si, devido à justa preocupação de que precisam do emprego, o que determina o privilégio do direito do mais forte - $\mathrm{o}$ patrão - e o prejuízo da saúde psíquicas das pessoas assediadas, os trabalhadores ${ }^{(1)}$.

Em suma, constatou-se, através dos estudos, que o assédio moral é caracterizado como uma violência psicológica que ocorre de maneira repetitiva sobre um indivíduo e por um período de tempo prolongado, e que apresenta como fatores de risco a idade, o sexo e o tempo de formação profissional do trabalhador, bem como as condições impostas pelo trabalho intensificado e precarizado.

\section{Assédio moral: consequências para a saúde do trabalhador da Enfermagem.}

No tocante às consequências do assédio moral para a saúde do trabalhador da Enfermagem, os estudos selecionados permitiram conhecer os principais danos físicos e/ou psicológicos. Essas consequências podem aparecer como distúrbios "psicossomáticos", os quais podem incluir: depressão; estresse; baixa autoestima; síndrome de burnout; insônia; fadiga; problemas gástricos, em especial, gastrite e úlcera; distúrbios cardiovasculares, como taquicardia e hipertensão arterial; dores; e, em casos extremos, o suicídio ${ }^{(17)}$.

Desse modo, muitos dos indivíduos assediados localizam o trabalho como cenário principal de tal prática, a qual é capaz de rebaixar a qualidade de vida dos trabalhadores, uma vez que são acometidos por grandes desordens psicológicas ${ }^{(18)}$.

Em um relato de experiência realizado com narrativas de 99 enfermeiros, verificou-se que dentre as respostas emocionais negativas geradas pelo assédio moral destacaram-se: estresse, ansiedade, raiva, humilhação, medo, perda de controle e sensação de impotência $^{(19)}$.

Em uma pesquisa realizada na Turquia, com a finalidade de verificar o assédio moral experimentado por enfermeiros que trabalham em unidades de saúde e os efeitos resultantes do fato, averiguou-se que as reações fisiológicas mais frequentes foram o cansaço e o estresse $(72,9 \%)$, dores de cabeça $(69,5 \%)$, falta de apetite $(53,5 \%)$ e queixas gastrointestinais $(52,9 \%)$. Em relação às reações emocionais, a mais enfatizada foi a tristeza extrema, estando relacionada a condutas hostis $(58,8 \%)$ e crises de choros $(52,5 \%)^{(20)}$. Logo, a tensão e um estado de permanente vigilância dos enfermeiros são as consequências mais frequentes e de maior intensidade relacionadas a tal prática ${ }^{(21)}$.

Nesse sentido, os enfermeiros correlacionam o assédio com a diminuição da qualidade do cuidado prestado ao paciente ${ }^{(19,21-22)}$. O paciente que depende de profissionais vitimados pelo assédio moral pode estar vulnerável a vários danos decorrentes do atendimento ineficaz, visto que as habilidades cognitivas e a capacidade de se relacionar dos enfermeiros, nestes casos, estão comprometidas ${ }^{(22)}$.

É preciso destacar que essa prática atenta contra os direitos humanos fundamentais, que incluem: o resguardo da liberdade dos direitos e garantias individuais; $\mathrm{o}$ atendimento às necessidades e direitos econômicos, sociais e culturais e a preservação de direitos à fraternidade e à solidariedade ${ }^{(17)}$. Em outras palavras, em casos de assédio moral, a vítima fica totalmente desprotegida e à mercê de um fenômeno destrutivo.

Diante do exposto, verifica-se que o assédio moral acarreta sérias consequências sobre a saúde mental do trabalhador, sendo esta de tal ordem que pode marcar negativamente e de maneira definitiva a vida da pessoa assediada, o que exige medidas de prevenção urgentes. Por outro lado, se reconhece que o assédio moral é uma epidemia invisível e essa invisibilidade traz como implicação a não mobilização de recursos de todas as naturezas para combatê-lo eficazmente ${ }^{(21)}$.

Finalmente, os comportamentos de violência dentro do local de trabalho necessitam de identificação precoce, para que novas políticas, de preferência públicas, sejam implementadas, visando a melhoria da qualidade de vida dos profissionais da saúde, no caso, os da Enfermagem.

\section{CONSIDERAÇÕES FINAIS}

Constatou-se que a discussão acerca do assédio moral no âmbito da Enfermagem está em amplo desenvolvimento, conforme evidenciam as publicações investigadas, nas quais a discussão sobre a temática tem ocorrido em vários países. $\mathrm{O}$ estudo mostrou que a prevalência do assédio moral na Enfermagem tem aumentado de maneira expressiva, acarretando sérias consequências, essencialmente psicológicas, para os profissionais desse campo.

Trata-se, pois, de um tema merecedor de novas investigações, sendo necessário que os pesquisado 
res desenvolvam pesquisas que permitam conhecer a fundo os elementos do mundo do trabalho que têm determinado tal agravo. Dessa forma, o estudo buscou contribuir para a divulgação das informações aqui abordadas e alerta para a necessidade da eliminação e prevenção de tal prática. Neste sentido, também cabe, aos trabalhadores da Enfermagem estar atentos e participantes na construção de estratégias que possam ser adotadas para evitar o assédio moral.

\section{REFERÊNCIAS}

1. Thofehrn MB, Amestoy SC, Carvalho KK, Andrade FP, Milbrath VM. Assédio moral no trabalho da enfermagem. Cogitare enferm. 2006;13(4):597-601.

2. Pedroso VG, Limongi AC, Martins FAS, Hrdlicka H, Jorge SM, Cornetta VK. Aspectos conceituais de assédio moral: um estudo exploratório. Rev. adm. saude. 2006;8(33):139-47.

3. Guimarães LAM, Rimoli AO. "Mobbing" (assédio psicológico) no trabalho: uma síndrome psicossocial multidimensional. Psic.: Teor. e Pesq. 2006;22(2):183-92.

4. Ozturk H, Sokmen S, Yilmaz F, Cilingir D. Measuring mobbing experiences of academic nurses: development of a mobbing scale. J Am Acad Nurse Pract. 2008;20(9):435-42.

5. Hirigoyen MF. Assédio moral: a violência perversa no cotidiano. 10 ed. Rio de Janeiro: Bertrand Brasil; 2008.

6. Dias HHZR. O “des"cuidado em saúde: a violência visível e invisível no trabalho da enfermagem [dissertação]. Florianópolis (SC): Universidade Federal de Santa Catarina; 2002.

7. Mendes KDS, Silveira RCCP, Galvão CM. Revisão integrativa: método de pesquisa para incorporação de evidências na saúde e na enfermagem. Texto Contexto Enferm. 2008;17(3): 758-64.

8. Fonseca RMP, Penishe ACG. Enfermagem em centro cirúrgico: trinta anos após criação do sistema de assistência de enfermagem perioperatória. Acta Paul. Enferm. 2009;22(4):428-33.

9. Torre EM, Días AG, Calvo MAC, Franco MDV, Requena RC, Cid AL. Valoración del riesgo psicosocial en las enfermeras de nefrología de los hospitales de Sevilla. Rev Soc Esp Enferm Nefrol. 2005;8(4):18-23.

10. Troncoso PM, SuazoVS. Enfermeras en riesgo: violencia laboral con enfoque de género. Index Enferm. [Internet] 2005;14(51) [acesso em 30 out 2012]. Disponível: http:// dx.doi.org/10.4321/S1132-12962005000300008

11. Vasconcellos IRR, Abreu AMM, Maia EL. Violência ocupacional sofrida pelos profissionais de enfermagem do serviço de pronto atendimento hospitalar. Rev. Gaúcha Enferm. 2012;33(2):167-75.

12. Cezar ES, Marziale MHP. Problemas de violência ocupacional em um serviço de urgência hospitalar da cidade de Londrina, Paraná, Brasil. Cad. Saúde Públ. 2006;22(1):217-21.

13. Chen WC, SunYH, Lan TH, Chiu HJ. Incidence and risk factors of workplace violence on nursing staffs caring for chronic psychiatric patients in Taiwan. Int. J. Environ. Res. Public Health. 2009;6(11):2812-21.

14. Berry PA, Gillespie GL, Gates D, Schafer J. Novice nurse productivity following workplace bullying. J nurs. scholar. 2012;44(1):80-7.

15. Barbosa R, Labronici LM, Sarquis LMM, Mantovani MF. Violência psicológica na prática profissional da enfermeira. Rev Esc Enferm USP. 2011;45(1):26-32.

16. Cahú GRP, Leite AIT, Nobrega MML, Fernandes MGM, Costa KNFM, Costa SFG. Assédio moral: análise de conceito na perspectiva evolucionista de Rodgers. Acta Paul. Enferm. 2012;25:(4):555-9.

17. Cahú GPR, Rosenstock KIV, Costa SFG, Leite AIT, Costa ICP, Claudino HG. Produção científica em periódicos online acerca da prática do assédio moral: uma revisão integrativa. Rev. Gaúcha Enferm. 2011;32(3):611-9.

18. Santos MAF, Siqueira MVS. Considerações sobre o trabalho e suicídio: um estudo de caso. Rev. bras. saúde ocup. 2011;36 (123):71-83.

19. Gaffney DA, DeMarco RF, Hofmeyer A, Vessey JA, BundinWC. Making things right: nurses' experiences with workplace bullying - a grounded theory. Nursing Research and Practice. 2012;(2012):1-10.

20. Yildirim A, Yildirim D. Mobbing in the workplace by peers and managers: mobbing experienced by nurses working in healthcare facilities in Turkey and its effect on nurses. J Clin Nurs. 2007;16(8):1444-53.

21. Xavier ACH, Barcelos CRV, Lopes JP, Chamarelli PG, Ribeiro SS, Lacerda LS, et al. Assédio moral no trabalho no setor de saúde do Rio de Janeiro: algumas características. Rev. bras. saúde ocup. 2008; 33(117):15-22. 
22. Castellon AMD. Violência laboral em enfermeiras: explicações e estratégias de enfrentamento. Rev. LatinoAm. Enfermagem. 2011;19(1):156-63. 